\title{
Protein-Protein Interaction between Glyoxalase II and Specific Redox Dependent Proteins through S- glutathionylation Modification ${ }^{\dagger}$
}

\author{
Laura Cianfruglia ${ }^{1}$, Cristina Minnelli ${ }^{2}$, Andrea Scirè ${ }^{2}$ and Tatiana Armeni ${ }^{1}$ \\ 1 Department of Clinical Sciences, Section of Biochemistry, Biology and Physics,Università Politecnica delle \\ Marche, Ancona, Italy; 1.cianfruglia@univpm.it (L.C.); t.armeni@staff.univpm.it (T.A.) \\ 2 Department of Life and Environmental Sciences, Università Politecnica delle Marche, Ancona, Italy; \\ c.minnelli@staff.univpm.it (C.M.); a.a.scire@univpm.it (A.S.) \\ * Correspondence: e-mail@e-mail.com; Tel.: +xx-xxx-xxx-xxxx \\ + Presented at the 1st International e-Conference on Antioxidants in Health and Disease, 01-15 December \\ 2020; Available online: https://cahd2020.sciforum.net/.
}

Published: 30 November 2020

\section{Introduction}

Glyoxalase II (Glo2), the second enzyme of Glyoxalase system, is an antioxidant glutathionedependent enzyme, that catalyzes the hydrolysis of S-D-lactoylglutathione (SLG) to form D-lactic acid and glutathione (GSH). GSH is the most important thiol reducing agent inside the cell. For its chemistry features GSH plays a crucial role not only in the cellular redox state but also in various cellular processes including protein S-glutathionylation. S-glutathionylation a process that involves the reversible formation of a mix disulphide-bridge between specific cysteine residues and GSH can be spontaneous or catalyzed by enzyme. S-Glutathionylation, also it is involved in protection of protein thiol groups from irreversible oxidation and play key role in redox regulation by activation/inactivation of different enzyme.

\section{Methods}

Glo2 and SLG were incubated with different proteins that are known to be glutathionylated, like malate dehydrogenase, actin or cytochrome c purified proteins.

\section{Results}

During the hydrolysis of SLG, in the active site of Glo2 there is unprotonated glutatione molecule (GS-) which can be transferred to protein target. These in vitro studies demonstrated high propensity of Glo2 to aggregate with other proteins through its catalytic site leading to an enzymatic regulation of S-glutathionylation in proteins of different origin and cellular compartmentalization.

\section{Conclusion}

Identification of active involvement of Glo2 in glutathionylation of different proteins. In this perspective, Glo2 can play a new important regulatory role in S-glutathionylation, acquiring further significance in cellular post-translational modifications of protein.

(C) 2020 by the authors; licensee MDPI, Basel, Switzerland. This article is an open access article distributed under the terms and conditions of the Creative Commons by Attribution (CC-BY) license (http://creativecommons.org/licenses/by/4.0/). 